\title{
Documentos hebreos de Plasencia
}

José Luis LACAVE

CSIC, Madrid

Entre los documentos de Plasencia que publica Marciano de Hervás ${ }^{1}$, el que figura con el número 5 incluye, cosida entre sus folios $2 \mathrm{v}$ y $5 \mathrm{r}^{2}$, una hoja escrita en hebreo, cuya transcripción junto con su traducción o transcripción española, según el caso, publicamos aquí.

El citado documento 5 contiene dos escrituras notariales, fechadas ambas en Plasencia el 4 de noviembre de 1461. Por la primera, doña Vellida, viuda de Yehudá Abenataf, en su propio nombre y en el de sus hijos Yentó y Abraham, su otro hijo Yuçef y su yerno Çid Bueno venden a Salamón Abenhabibe, otro yerno de doña Vellida, una casa que poseen en la calle de la Rúa. La segunda es la toma de posesión por parte del mencionado Salamón Abenhabibe de la citada casa. Ambas escrituras se firman ante Diego López de Ciudad Rodrigo, escribano real y escribano público de Plasencia. Para mayor comprensión de los textos hebreos, añadamos que la escritura de venta comienza: «Sepan quantos ... como yo doña Vellida ... por mi e en nombre de Yento Abenataf, mi fijo, cuyo poder tengo .... ${ }^{3}$.

El asunto parece bastante claro. Doña Vellida ha enviudado de don Yehudá Abenataf, probablemente en el mismo año 1461 o quizá el año anterior, quedando en una situación económica no muy boyante. Al quedar viuda, tiene 2 hijos -Yentó y

${ }^{1}$ Véase su artículo «Documentos sobre los judíos de Plasencia en el Archivo Catedralicio (1411-1492)», Sefarad 59 (1999) págs. 53-76 y 263-307.

2 Así lo manifiesta HeRVÁs «Plasencia» págs. 68-71 y 278, nota 165.

3 Véase HERVÁs «Plasencia» pág. 275. 
Abraham- que viven con ella y al parecer menores de edad; otro hijo - Yuçef- ya independizado y dos hijas casadas, una con Çid Bueno y otra, llamada Ester, con Salamón Abenhabibe, quien parece ser hombre adinerado. Por todo ello, la familia concibe la idea, bien común entre los judíos hispánicos de entonces, de vender la propiedad de la casa que fue del fallecido don Yehudá y de su mujer doña Vellida a Salamón, con la condición de que la viuda siga viviendo en ella mientras quiera. De hecho, en la escritura se dice que tras la ceremonia de toma de posesión el citado Salamón «dexo de su mano a la dicha doña Vellida para que biuiese e morase en ellas mientras su voluntad fuese» ${ }^{4}$.

En cuanto a la hoja escrita en hebreo ${ }^{5}$, que es el verdadero objeto de estas páginas, contiene 2 documentos, uno escrito en hebreo y el otro en aljamía hebraicocastellana. El primero es una escritura fechada en Plasencia el 26 de septiembre de 1461 -es decir, 39 días antes de la escritura de compraventa arriba citada- por la que Yom Tob ben Nataf (Yentó Abenataf) hace cesión a su madre, doña Vellida, de toda la herencia que le corresponde en los bienes de su padre, y en especial, de la parte que le corresponde de la casa «que tenía mi padre, el citado don Yehudá [ben Nataf], su alma descanse en el Edén, en la calle que dizen la Rúa». Ni que decir tiene que los linderos de esta casa son los mismos que figuran en la escritura de venta. En definitiva, se trata del poder que doña Vellida afirma tener de su hijo Yentó en la dicha escritura de compraventa. Por eso se cosió a ella el documento hebreo.

El segundo documento, el aljamiado, fechado en Plasencia el 22 de septiembre de 1462, es decir, casi un año después de la venta de la casa, es un albalá de pago por el que doña Vellida admite haber cobrado de su yerno Salamón Abenhabibe el precio estatuido en la escritura de compraventa. Lo curioso es que en la dicha escritura se dice que el precio es de 20.000 maravedíes ${ }^{6}$ y en este albalá -firmado casi un año después,

\footnotetext{
4 Véase Hervás «Plasencia» pág. 278 (fol. 5v).

${ }^{5}$ En realidad eran en su origen 2 hojas que se cosieron horizontalmente la una a la otra, formando así una sola, a su vez cosida luego al documento romance, el mencionado núm. 5.

6 Véase HERVÁs «Plasencia» pág. 276 (fols. 1-1v).
} 
recuérdese- se dice que es de 16.000 maravedíes. Tal vez lo que ocurra es que 16.000 es la cantidad que correspondía a doña Vellida, pues junto con ella vendían también su hijo Yuçef y su otro yerno Çid Bueno. De todos modos, llama la atención la diferencia, que, por otra parte, no se explica.

Lo que sí se explica en el albalá es cómo ha cobrado doña Vellida los 16.000 maravedíes. Una parte la recibió en mano ante Diego López, el escribano ante quien pasó la compraventa; otras partes, haciendo que el comprador amortizase ciertas deudas que ella tenía con diversos acreedores: su otro yerno Çid Bueno, Alonso Trigo, Gutierre González y Šemuel Abençur; y una última parte la recibe en varas de paño, lo que quizá indica que doña Vellida y su yerno andaban metidos en el comercio de paños.

Cada uno de estos documentos hebreos lleva la firma de dos testigos. Uno de ellos, que se repite en ambos documentos, Yosef bar Yehudá, podría ser el hijo mayor de doña Vellida, viuda de Yehudá Abenataf, aunque Yosef bar Yehudá es un nombre muy común.

[1] אנו עדים החותמין [החתומין por] למטה כן היה שאמר לנו יום טוב

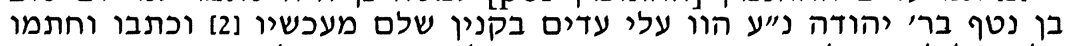
עלי בכל לשון של זכות ותנו ביד דונייא ויליידה אימי אלמנת דון יהודה אבי הנזכר נ"ע [3] להיות בידה לזכות וליע ולראיה מחמת שרציתי ברצון נפשי ובהשלמת דעתי בלי שום זכר אונס כלל אלא [4] בלב שלם ובנפש חפצה ודיה ודעת שלימא ועין יפה וגוף בריא ומחלתי לה מחילה גמורה על כל כל ירושה הראוית

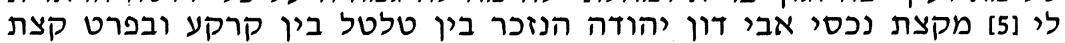
בית אחד שיש לאבי דון יהודה הנזכר נ"ע אינלה [6] קאליי קי דיזין לה רואה קאליי דילה סאפאטיריאה שמצרני הבית ? [lectura dudosa] מצד אחד בית של דון חיים מושודו ס"ט ומצד אחד [7] בית די מרטין גונונסאליץ על הכל מחלתי לה מחילה גמורה שלימא שרירא וקיימת חתוכה וחלוטה דלא למהדר [8] ביה להשנאה מנה לעלמין מחילת בריא מחילת עלמין מחילת פרהסיא שאין בִה חזרה וחרטה לעולם מחילת מנוקה [9] ומשופה מכל ערעור ומכל ומל

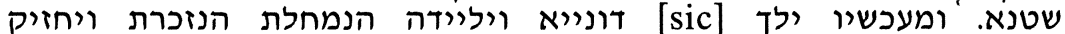
[sic] במחילה זו הנזכרת [10] שמחלתי לה כפי שנזכר ויזכה בה לעצמה

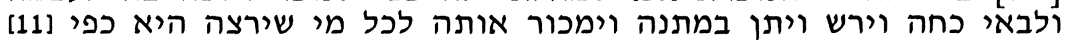
שנזכר ולא שיירתי בה לעצמי ולבאי כחי ולא ליורשי אחרי לא קול ולא

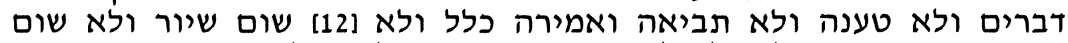
זכות בשום ענין בעולם ולא ליורשי אחרי וכבר סלקתי לעצמי ורי ורשותי וזכותי

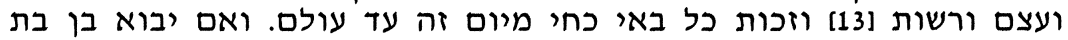
אח אחות קרוב רחוק יהודי או גוי בין בכתב בין בעל פה ויערער [14] 


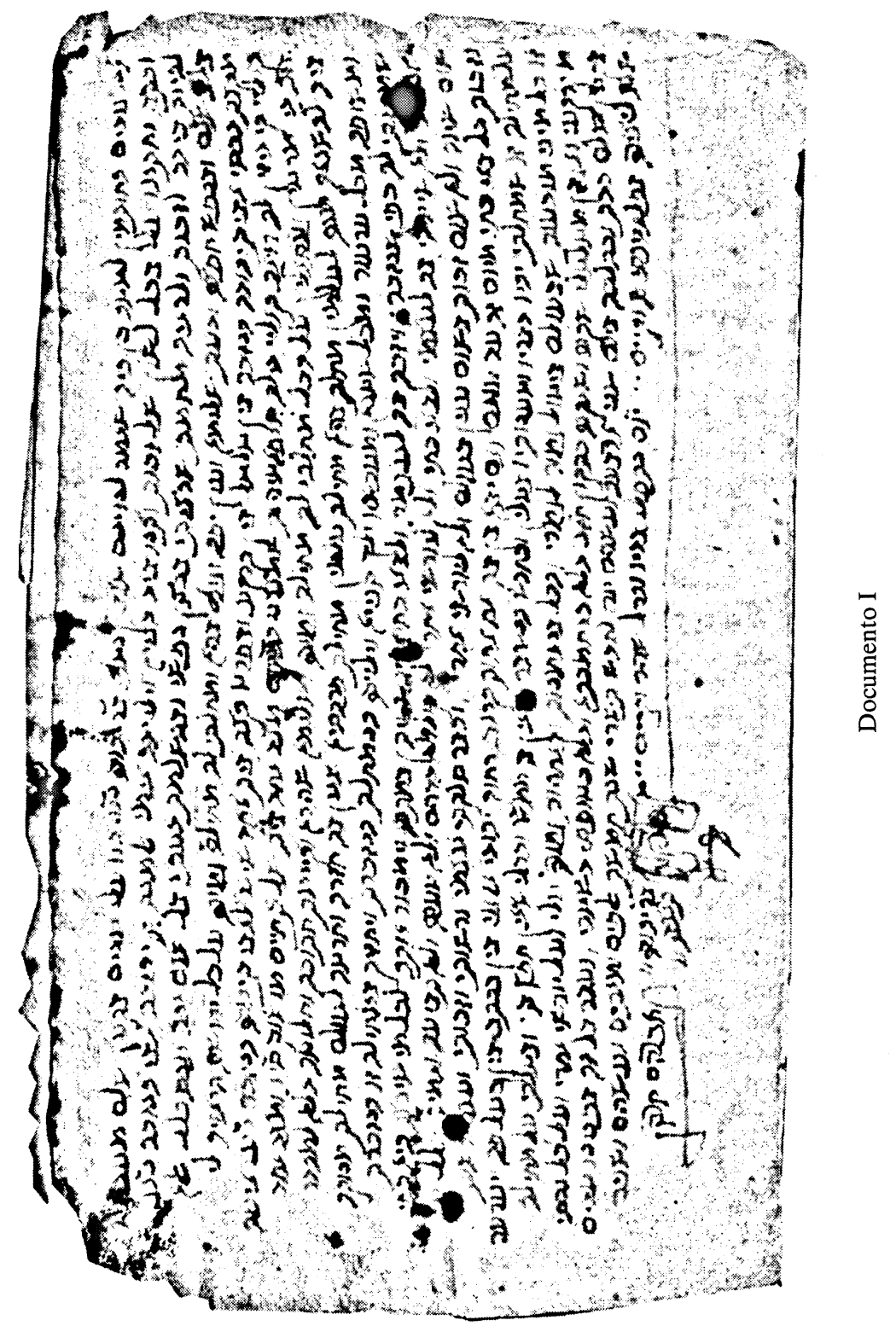




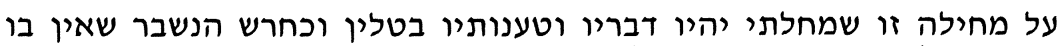

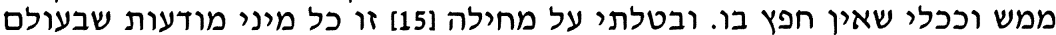

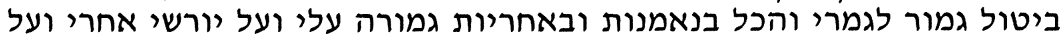

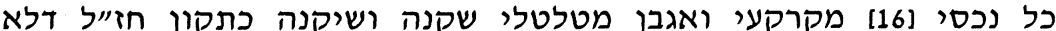

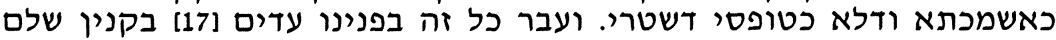

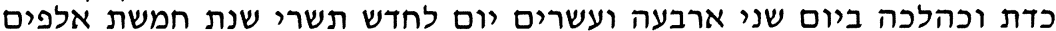

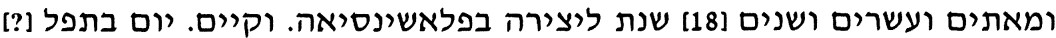
בדיו [?] והכל שריר וקיים. יוסף בר' יהודה. אברהם לאש חרבון.

[1] Nosotros, los testigos abajo firmantes, [declaramos que] así ocurrió: Nos dijo Yom Tob ben Nataf [Yentó Abenataf], hijo de Yehudá, su alma descanse en el Edén: Sedme testigos con quinyán completo desde ahora, [2] escribidme y firmadme en todo lenguaje de derecho y dádselo a donya ${ }^{7}$ Vellida, mi madre, viuda de don Yehudá, mi citado padre, su alma descanse en el Edén, [3] para que esté en su poder, sirviéndole de constatación de derechos y de prueba, por cuanto que yo quiero, voluntariamente y con plena consciencia, sin ningún género de coacción en absoluto, sino [4] de todo corazón, con buena voluntad y conocimiento pleno, de buen grado y en perfecto estado de salud, cederle a ella con total cesión toda la herencia que me corresponde [5] de una parte de los bienes de mi padre, el citado don Yehudá, tanto en bienes muebles como inmuebles, y en especial, de la parte de una casa que tenía mi padre, el citado don Yehudá, su alma descanse en el Edén, en la [6] calle que dizen la Rúa calle de la Zapatería, cuyos linderos de la casa [lectura dudosa] son: por un lado, casa de don Hayim Moxudo, su fin sea para bien, y por otro lado [7] casa de Martín Gonçalez. Todo se lo cedo con cesión total y completa, firme y permanente, definitiva e irreversible, que no se puede revocar [8] ni cambiar nada de ella nunca, cesión de un hombre sano, permanente y pública, de la que no puede uno retractarse ni arrepentirse nunca, cesión limpia [9] y pulida de toda impugnación o acusación. Y desde ahora mismo vaya donya Vellida, la mencionada cesionaria, y coja esta cesión citada [10] que yo le cedo, según se ha dicho, y adquiera los derechos en ella para sí misma y para sus representantes, pueda here-

${ }^{7}$ Señalo en cursiva las palabras castellanas escritas en aljamiado. 
darla, darla en donación o venderla a todo aquel que ella quiera según [11] se ha dicho, no reservándome yo en ella ni para mí ni para mis representantes ni para mis herederos después de mí ni voz ni demandas, ni objeción, ni reclamación ni dicho alguno, ni [12] reserva alguna, ni ningún derecho en manera alguna, ni para mis herederos después de mí, pues ya he apartado yo [de la cesión] mi persona, mi faculțad y mi derecho, así como la persona, la facultad [13] y el derecho de todos mis representantes desde hoy y por siempre. Y si llegara alguien, un hijo, hija, hermano, hermana, pariente cercano o lejano, un judío o un gentil, ya sea por escrito u oralmente, e impugnara [14] esta cesión que yo cedo, sean sus palabras y sus demandas nulas, como la vasija rota que no hay en ella realidad y como el cacharro inútil. $Y$ yo invalido contra esta cesión [15] todo tipo de protestas que haya en el mundo, de una manera absolutamente total. Todo con la garantía y el aval totales recayendo sobre mí y sobre mis herederos después de mí, sobre todos mis bienes [16] inmuebles, y por vía de ellos, los muebles, habidos y por haber, de acuerdo con las prescripciones de nuestros sabios de bendita memoria, pues no es esto como una promesa meramente teórica ni como un simple formulismo documental. Y todo esto sucedió ante nosotros, testigos, [17] con quinyán completo, de acuerdo con la ley y con las prescripciones rabínicas, el lunes, día 24 del mes de tišrí del año 5222 [18] de la Creación [26 sept. 1461] en Plasencia. Y es firme ... Y todo es firme y permanente. Yosef bar Yehudá. Abraham Harbón.

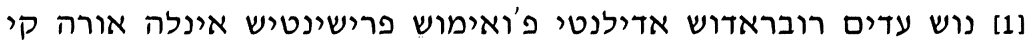

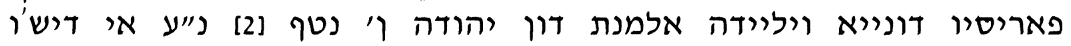

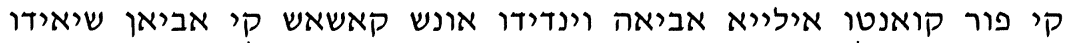

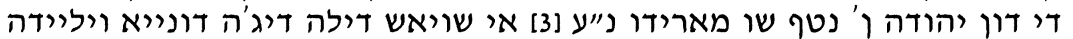

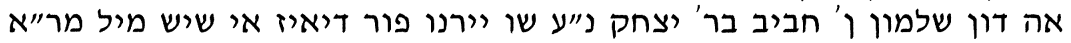

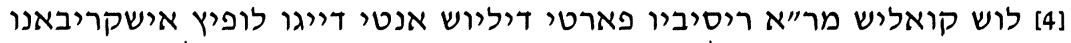

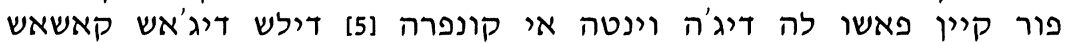

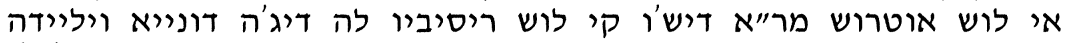

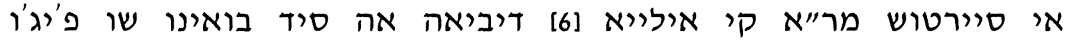

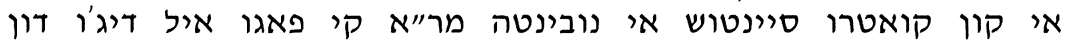


שלמון פור שו מנדאדו [7] דילייא אה אינה אלונשו טריגו אי קו קון סיינטו.

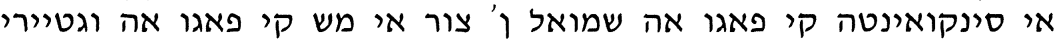

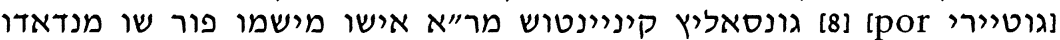

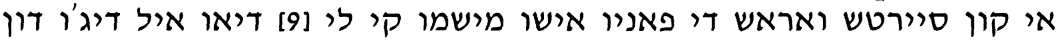

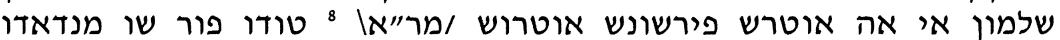

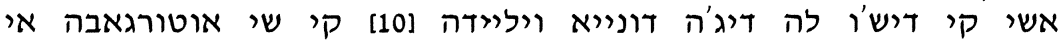

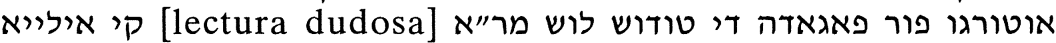

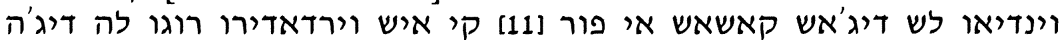

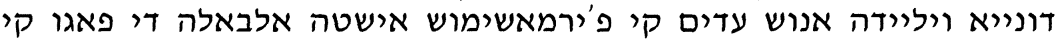

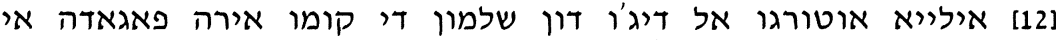

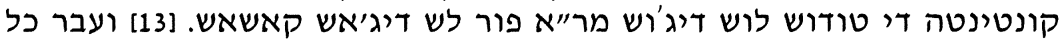

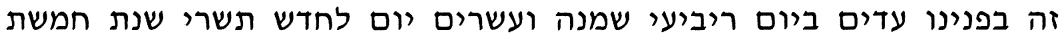

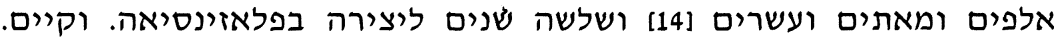

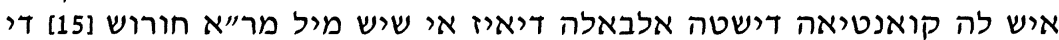

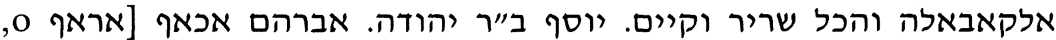

[lectura muy dudosa

[1] Nos, [los] testigos ${ }^{9}$ robrados adelante, fuimos presentes en la hora que pareçio donya Vellida, viuda de don Yehuda ben Nataf [Abenataf] [2], su alma descanse en el Edén, e dixo que por cuanto ella habia vendido unas casas que habian seido de don Yehuda ben Nataf, su marido, su alma descanse en el Edén, [3] e suyas de la dicha donya Vellida a don Salamon ben Habib bar Yișhac [Salamón Abenhabibe], su alma descanse en el Edén, su yerno, por diez e ses mil maravedis, [4] los cuales maravedis reçibio parte dellos ante Diego Lopez, escribano por quien paso la dicha venta e conpra [5] de las dichas casas, e los otros maravedis dixo que los reçibio la dicha donya Vellida, e çiertos maravedis que ella [6] debia a Çid Bueno, su fijo, e con cuatro çientos e nobenta maravedis que pago el dicho don Salamon por su mandado [7] della a Alonso Trigo, e con çiento e çincuenta que pago a Šemuel ben Çur [Abençur], e mas que pago a Gutierre [8] Gonçalez quinientos maravedis eso mismo por su mandado, e con çiertas varas de panyo eso mismo que le [9] dio el dicho don Salamon e a otras personas otros Imaravedis/, todo por su mandado, asi que dixo la dicha donya Vellida [10] que se otorgaba e otorgo por pagada de todos los maravedis [lectura dudosa] que ella vendio las dichas

\footnotetext{
${ }^{8}$ Esa palabra encima de la línea.

${ }^{9}$ Marco en cursiva las palabras y frases en hebreo.
} 


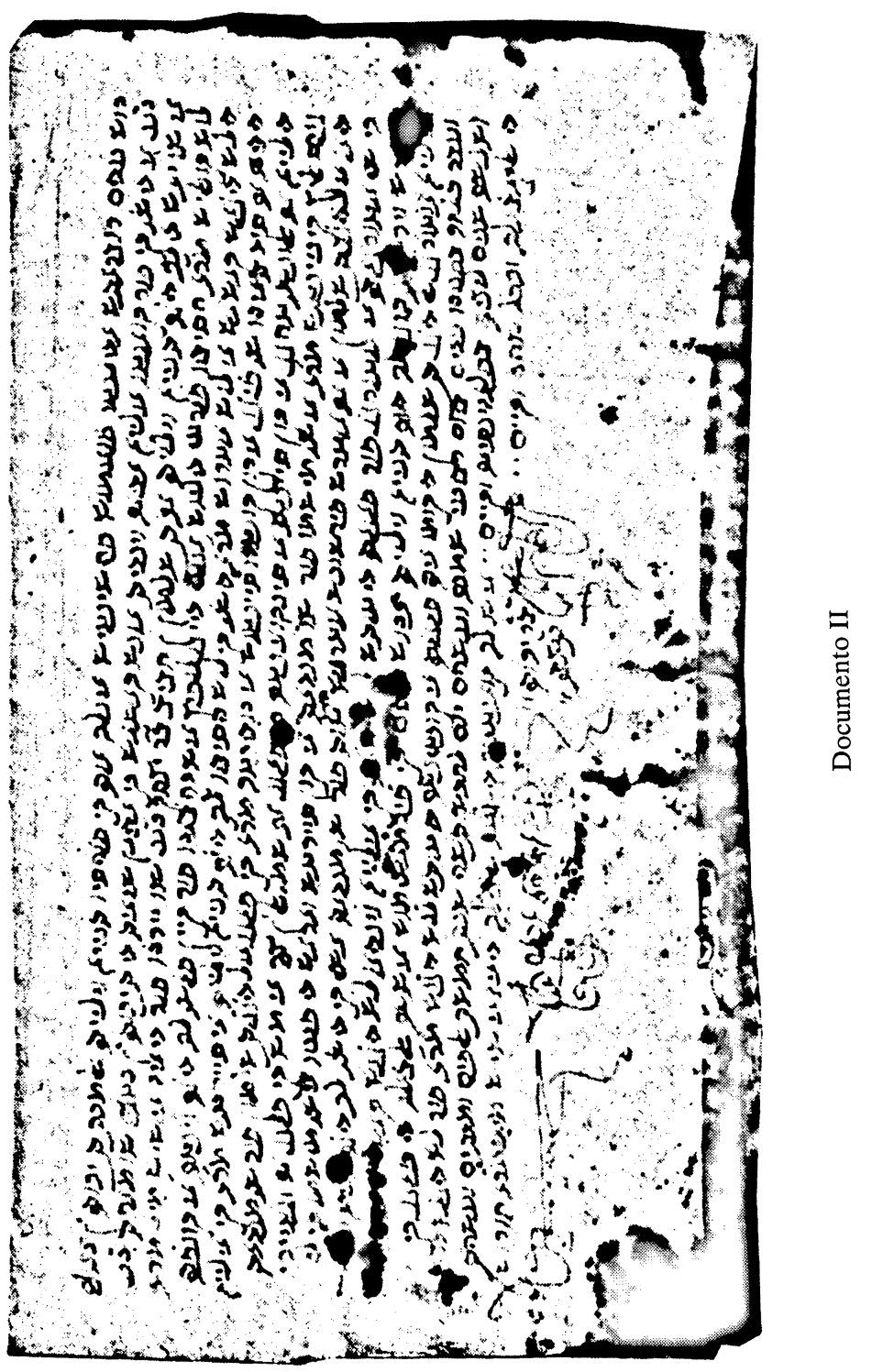


casas, e por [11] que es verdadero, rogo la dicha donya Vellida a nos, [los] testigos, que firmasemos esta albala de pago que [12] ella otorgo al dicho don Salamon de como era pagada e contenta de todos los dichos maravedis por las dichas casas. [13] Y sucedio todo esto ante nosotros, testigos, el miércoles día 28 del mes de tišrí del año 5223 [14] de la Creación [22 sept. 1462] en Plasencia. $Y$ es firme. Es la cuantia desta albala diez e ses mil maravedis horos [15] de alcabala. $Y$ todo es firme $y$ permanente. Yosef bar Yehuda. Abraham Acaf [o Araf, lectura muy dudosa].

\section{RESUMEN}

Publicación de dos documentos, uno en hebreo y el otro en aljamía hebraicocastellana, que se hallan cosidos a un documento de compraventa que se guarda en el Archivo Catedralicio de Plasencia; documento este último publicado en estas mismas páginas de Sefarad por Marciano de Hervás. El documento en hebreo, fechado en Plasencia el 26 de septiembre de 1461, es un poder que Yentó [Gento] Abenataf otorga a su madre, doña Vellida, para que disponga libremente de lo que le corresponda en la herencia de su fallecido padre, y en particular, de lo que le corresponda en la casa objeto de la compraventa. El documento aljamiado, fechado en Plasencia el 22 de septiembre de 1462 , es un albalá de pago por el que doña Vellida admite haber cobrado el precio de la casa vendida.

\section{SUMMARY}

The present publication includes two historical documents, one in Hebrew, the second in transliterated Hebrew-Spanish, discovered in the Plasencia Cathedral Archives sewn to a bill of sale. The bill of sale was published in Sefarad 59 (1999) pp. 275-279 by Marciano de Hervás. The Hebrew document, dated in Plasencia on September 26, 1461, is a power of attorney signed by Yento Abenataf authorizing his mother doña Vellida to freely dispose of the inheritance pertaining to his deceased father and, most particularly, his share of the sale of the house. The aljamiado document, dated in Plasencia on September 22,1462, is a public document attesting to the payment that dona Vellida admits having received for the sale of the house. 